\title{
Management Model for Assistive Technology Development in a Brazilian Public Education Network
}

\author{
Elton Moura Nickel ${ }^{1, *}$, Marcelo Gitirana Gomes Ferreira ${ }^{1,2}$, Fernando Antônio Forcellini ${ }^{2}$, Vilson João Batista ${ }^{2}$ \& \\ Vinícius Domingues Buch ${ }^{1}$ \\ ${ }^{1}$ Department of Design, State University of Santa Catarina, Florianopolis, Brazil \\ ${ }^{2}$ Department of Production Engineering, Federal University of Santa Catarina, Florianopolis, Brazil \\ *Corresponding author: Departamento de Design, Universidade do Estado de Santa Catarina. Av. Madre Benvenuta, \\ 2007-Itacorubi, CEP: 88.035-001, Florianópolis-SC, Brazil. Tel: 55-48-3321-8000. E-mail: eltonnickel@gmail.com
}

Received: August 25, $2014 \quad$ Accepted: September 16, $2014 \quad$ Online Published: October 7, 2014

doi:10.5430/mos.v2n1p14 URL: http://dx.doi.org/10.5430/mos.v2n1p14

\begin{abstract}
This paper is embedded in an interdisciplinary context, with the aim of promoting an improvement to the area of product development and services with Assistive Technology (AT). It appears that aspects of managing the development of assistive technology have lagged behind rising demand for such resources, including the education sector, in which no institution of education in Brazil has the right to refuse students with disabilities. Therefore, this research aims to develop a management model for the development of technologies that promote the inclusion of students in the school systems in order to make the effort involved in providing assistive technology to the end user. The strategy chosen for this was the case study, this being on the collection of data about the current availability of AT for students with cerebral palsy. The case selected was the public education network in a Brazilian municipal city, whose data will subsidize the development of the management model to their adequacy to the education and government reality.
\end{abstract}

Keywords: management model; assistive technology; inclusive education

\section{Introduction}

To design any product, produce it properly and still meet all the needs of their customers is not something simple. It requires organization, insight and commitment on the part of the development team. Therefore, much more careful should be the work of who develops products and services to meet permanent special needs, that is, the development of Assistive Technology (AT) which, by definition, aims to assist - help, support, give support - to the disabilities of their end-user (Cook \& Hussey, 2002).

In recent years, the issue of AT has been supported by a growing number of events including those organized by International Association for Universal Design, who performed their third international conference in 2010, in Hamamatsu, Japan, and the Institute for Human Centered Design, with its initiative for the conference Desingning for the 21st Century in Rio de Janeiro, Brazil. As a result, there was a call for papers in early 2008 and 14 papers were subsequently accepted for publication. These were grouped in issue 2 and 3 of volume 21 of Journal of Engineering Design, April 2010, in four subjects of active research in the inclusive design area. The papers published under the theme 'design tools', such as Marshall et al. (2010), Johnson, Clarkson \& Huppert (2010), Carse, Thomson \& Stansfield (2010), Gyi, Cain \& Campbell (2010), Afacan \& Demirkan (2010) and Goodman-Deane, Langdon \& Clarkson (2010), are more directly related to the theme of AT covered in this work (Clarkson \& Coleman, 2010).

In this context, education is a social activity in which there is a major development need of assistive technology. In Brazil, the Federal Law 7.853/1989 ensures that no educational institution has the right to refuse students with disabilities. So it is up to the school to adapt its physical and pedagogical structure to receive all students without distinction. However, even the best initiatives have bogged down in issues that delay or limit their actions, as the difficulty in capturing financial resources, the long delays involved in meeting the specific demands and lack of 
alternatives more financially affordable and with the quality that really meet the needs of its audience.

Still, it was detected as a major need in public schools to support efforts by family and teachers to provide the inclusion of students with multiple disabilities, most of whom are students with cerebral palsy (CP). The CP is a non-progressive chronic infantile encephalopathy or neuromotor dysfunction resulting from damage to the developing brain, leading to disturbances in motor function, tonus and posture (Fonseca \& Lima, 2004).

Therefore, the objective of this work is to systematize the activities involved in the development of assistive technology aimed at the demand of students with cerebral palsy enrolled in a public educational network in Brazil. The result of this systematization is presented as a management model, called Management Model for Assistive Technology Development (MAT), developed to serve as a reference for education managers and caregivers of students with CP.

\section{Method}

We chose to implement a single strategy to systematize the achievement of the main results of this work, namely: the case study. This choice is supported by the very versatility of the method described by Stoecker (1991) as a method that covers everything, involving a logical planning and specific techniques for collecting and analyzing data.

The system applied for planning and conducting the case study was proposed by the COSMOS Corporation and structured by Yin (2003), composed of three phases: 1) Definition and Planning, 2) Preparation, collection and analysis and 3) Analysis and conclusion. Figure 1 shows these phases and the details of the activities involved in the case study method.

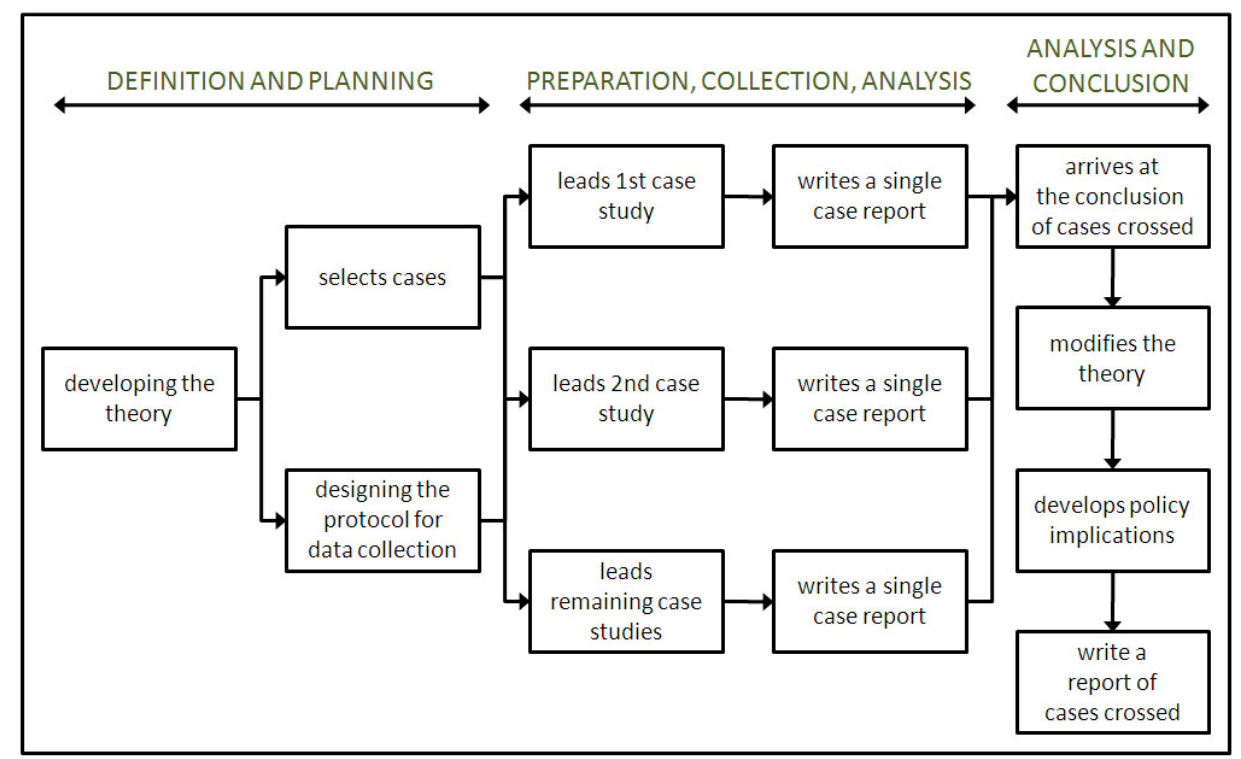

Figure 1. Case Study Method of COSMOS Corporation (adapted from Yin, 2003, p. 72)

As seen in the case study method, previous development of theoretical propositions is beneficial for the research conduction. Although the theory developed should not be unchangeable, it will be useful for the correct selection of cases and in drafting the protocol for data collection, making thus the Definition and Planning phase.

In this research, the theory developed concerns to a MAT framework, a previous structure of the management model, which is based on current literature and the experience gained from the research groups and institutions related to the theme. The initial theory as the basis for the development of the management model involves the main project stages required for the development of specific assistive technology in the school context, using the logic widespread in the literature area of Product Development Process (PDP).

After the establishment of the theory, we defined some criteria for the selection of individual cases that could contribute with information for the MAT development. The selected municipal educational network is the central case to be studied, and in education units across the city is where are find the professionals directly involved with the needs of students with disabilities and who participate in the solicitation of products and services to government.

Once aware of the study, we started to contact the managers of the units with students with the appropriate profile for 
the research sample, namely: students 3-11 years with cerebral palsy and a history of use of products or services with assistive technology in mainstream educational network. It was also defined, based on the proposed Yin (2003), which between three and five individual cases would be sufficient for the crossing of the data obtained.

After selecting the individual cases, it was planned how to obtain the necessary data from the people involved in the process. Among the strategies, was developed a questionnaire to be used, in semi-structured interview, for the pedagogical coordination of the teaching unit (composed of directors, coordinators and/or multimedia room teachers), one for teachers (auxiliary and / or room) and one for the family of the examined student with disabilities in order to check the different points of view regarding the process. To prepare the questionnaires were listed some criteria or requirements that should be addressed to improve the current process and refinement of the MAT. Therefore, after conducting a case study in the field, we obtained a list of requirements, captured from model and process' own customers to defining the final version of the MAT. The list of requirements can be obtained in research by Nickel (2012).

\section{Results}

This topic describes the final version of the Management Model To Assistive Technology Development (MAT), designed to meet current management needs for development of products and services with assistive technology for students with cerebral palsy in a municipal regular educational network in Brazil. The MAT is presented in this topic in order to detail the different constituent stages of the model from its fragmentation in sequential activities, organized on the basis of deliveries or results, needed for the continuation of each project initiated.

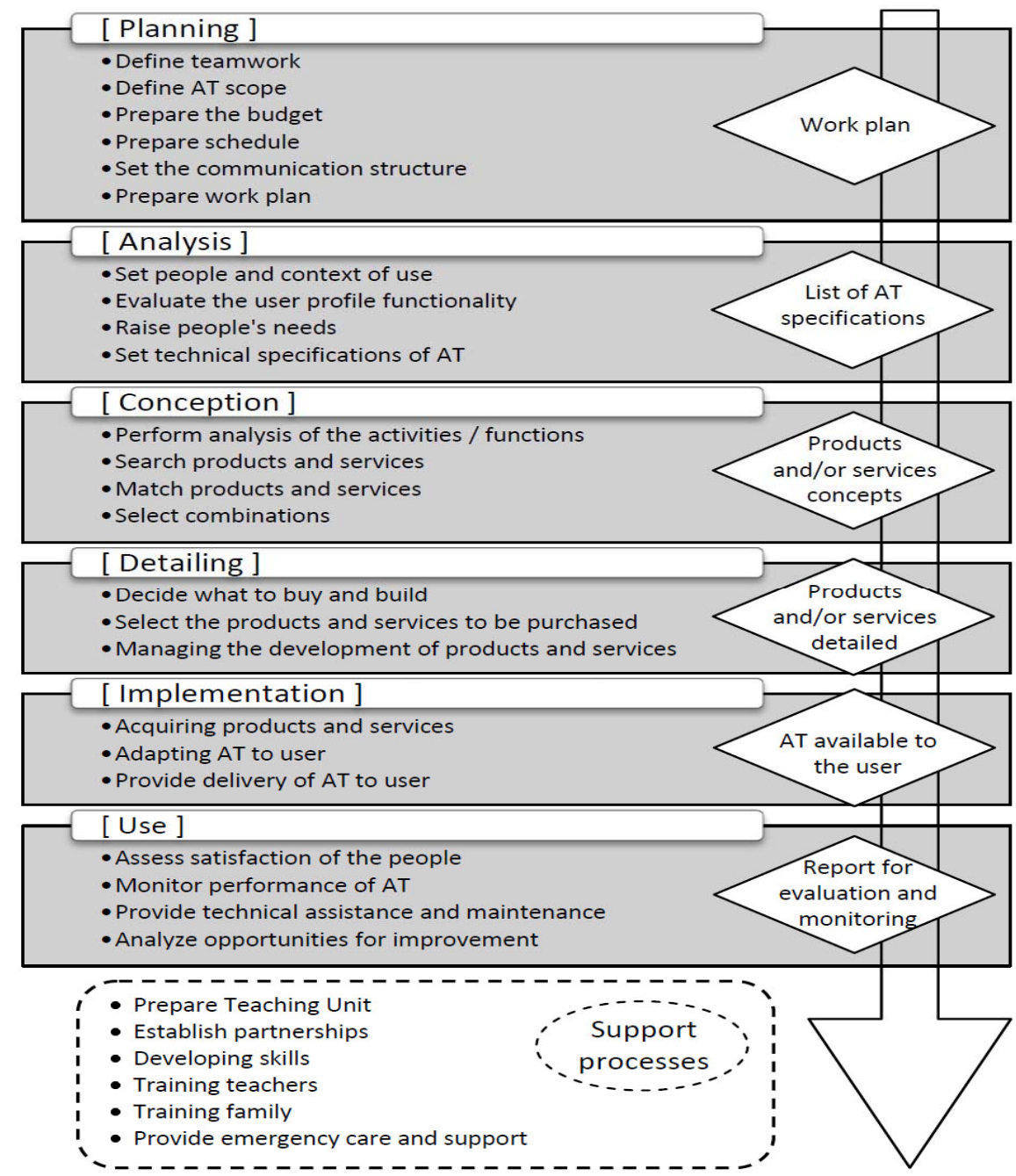

Figure 2. Graphical Representation of Model Management to Assistive Technology Development (MAT) 
It is hoped that with the data collected in the field and acquired experience, it will be possible to develop a complete management model, accurate and thorough but, at the same time, clear, of rapid assimilation and easy reference, for the benefit of all those involved in current process of inclusion in regular educational networks in Brazil. Figure 2 shows an overview of the model through a graphical representation which summarizes their main components.

In order to organize the deliveries previously defined in the MAT framework, it can be observed in Figure 2 the distribution of the MAT in six project stages, namely: 1) Planning, 2) Analysis, 3) Conception, 4) Detailing, 5) Implementation and, 6) Use. Still, six processes are proposed to support the development of assistive technology for the school system in question. These processes are not included as model activities by happening in parallel to a specific project and its results extend to multiple projects in a single teaching unit, pole or municipality.

As detailed in Figure 2, the Planning Stage is implemented through the activities of 'Define teamwork', 'Define AT scope', 'Prepare the budget', 'Prepare schedule', 'Set the communication structure' and 'Prepare work plan '. The set of all information obtained from these activities is the Work Plan. The Work Plan for this project is equivalent to the Product Project Plan, commonly used in the area of the PDP, while the necessary adjustments are made to the design reality in the study area.

At this stage it is administered, in an integrated manner, several knowledge required to a complete management of the project that is initiated. According to the Project Management Body Of Knowledge (PMBOK), these knowledge involve: scope, time, cost, quality, human resources, project communications, risk management, foreign acquisitions and the integration of all these areas. Still, it is important to relate the Planning Stage to other disciplines and practices of management (PMI Standards Committee, 2000).

The analysis stage includes the activities listed in Figure 2, 'Set people and context of use', 'Evaluate the user profile functionality', 'Raise people's needs' and 'Set technical specifications of AT'. This analytical stage of the project has to do especially with the lifting and handling of the requirements of the customers of the product or service that is being developed, whether internal, intermediaries or external.

It is noted in the literature a line of systematic procedures with respect to the lifting and handling of customer's requirements. Classical authors such as Pugh (1990), Roozenburg \& Eekels (1995), Baxter (1995), Pahl \& Beitz (1996), Otto \& Wood (2001), among others, directly or indirectly, offer the following activities to achieve this stage of analysis: 'definition of customers',' identification of customer requirements' and 'obtaining the design specifications'. Thus, the end result of the procedures is a list of design specifications, which have the aim of guiding the next stages of development, serving as a criterion for decisions made throughout the project.

Then, Analysis Stage, as presented at the MAT, is the equivalent stage of the classic PDP, and the terminology applied was adequate to the reality of research, by simplifying technical terms and direct the results to the area in question. Still, a specific activity was added to the procedures line commonly referenced in the PDP. It is the activity 'Evaluate the user profile functionality', whose main task is to health professionals such as physiotherapists, occupational therapists and doctors. The data obtained in this activity, therefore, together with the other requirements of the people involved, may serve as the basis for obtaining the technical specifications of the developing AT.

In Figure 2, the conception stage is completed after the completion of four activities considered essential for the development of the new product or service concept, namely: 'Perform analysis of the activities / functions',' Search products and services', 'Match products and services' and 'Select combinations'. In the PDP literature, this stage of a new product development is also known as Conceptual Design. In the use context of the MAT, we tried, besides simplify technical terms, reduce the complexity to make more dynamic the execution of this important stage of the project.

Baxter (1995) explains that the Conceptual Design aims to produce design principles that meet the basic benefits offered. The resulting product of this process should be sufficient to meet customer requirements and differentiate themselves from the market. In this stage are developed the basic lines of form and function of a new product. It is on this basis that the MAT is proposing the implementation of related activities, noting that the process of search and selection of resources and services for the inclusion of students in the contemplated school system may involve existing resources and available for purchase, and the development of new concepts.

The Detailing Stage, as shown in Figure 2, involves the activities of 'Decide what to buy and build', 'Select the products and services to be purchased' and 'Managing the development of products and services'. Baxter (1995, p. 231-232), the Detailed Design determines how the product will be produced. This step involves the "decision to making (to produce in the company) or buy third-party components." For each of the detailed components, "there must be a description of the production process (operations), the tools to be used and the materials used." 
For the implementation of the Detailing Stage activities, inserted in the MAT, the proposal is summarized in the development team decide what resources and services must be purchased and which should be developed. If the decision is to develop, the MAT proposes to operate a new development process based in the areas of design and engineering of products and services through traditional methodologies appropriate to the context. It is not objective of this study, therefore, to propose a new model or method for developing assistive technology resources for the sector of capital and consumer goods, but specifically for the reference of the mainstream educational network professionals.

After Detailing Stage, therefore, the developing product or service should have been completely defined, and if the decision has been to develop a new concept, the resource should have been produced and be available for purchase. The next stage the MAT proposed, as shown in Figure 2, is called the Implementation Stage, which is completed after the delivery of developed assistive technology to the end user. The activities that constitute the Implementation Stage are: 'Acquiring products and services', 'Adapting AT to user' and 'Provide delivery of AT to user'.

Just as it is important for a commercial product that there is a stage of product launch, where planning and designing the processes of sales and distribution, customer services and technical assistance and marketing campaigns necessary for placing the product on the market, something similar occurs with an AT designed for the school network (Rozenfeld et al., 2006). The aspects of the implementation, or effective delivery of this resource must be carefully planned and executed so as to adjust the outcome of the process to the applicant.

An important activity, for example, proposed to precede the activity of deliver the AT to the user, is to adapt it to the applicant student, where tests and checks will be done on whether the resource acquired is meeting the specifications and requirements raised in the beginning of the process. Thus, the resource delivery will only occur when the development team is certain that the product or service is set to the user, after possible adaptations that can only be observed in the physical interaction between the student and the AT.

The MAT is done with the important Use Stage, which involves 'Assess satisfaction of the people', 'Monitor performance of AT', 'Provide technical assistance and maintenance' and 'Analyze opportunities for improvement.' This stage is equivalent to post-development macro stage proposed in the PDP literature, which ensures the understanding of the entire product life cycle. At this point, the developed product or service is already in full use by the end user. To Rozenfeld et al. (2006, p. 436), monitoring the use of a product or service has, as main objective, to follow its performance, to identify "needs or opportunities for improvement and ensuring that its withdrawal would cause the least possible impact on consumers, business and environment."

Products and services with assistive technology, especially, have the intrinsic need for ongoing assessments are performed in its context of use. In addition to the postural adjustments, mobility and other important information by health professionals, students with disabilities often require support from family and teachers to perform their daily activities. An assessment of other customers satisfaction of the acquired feature is also key to improving the performance of developed AT, in order to meet the various existing needs.

At the bottom of Figure 2, in which MAT is graphically represented, one can observe a table of six items named "Process Support '. These processes concern the broader actions of inclusion, the results extend to the entire school system and community which will implement it. The Support Processes that make up the MAT are:

Prepare Teaching Unit: preparing for the school to receive students with any disability who enroll in the network. This preparation should occur in all aspects deemed essential to the promotion of autonomy, mobility, learning, communication and everything else that can generate quality of life and inclusion to the students enrolled.

Establish partnerships: making effective partnerships needed for educators to provide the necessary service on the network, beyond the aspects that involve their actual competence, ie, the didactic and pedagogical issues in the process of educational inclusion. Especially the health area has been identified as having essential skills for an adequate specialized educational service by the teaching units, in parallel with projective professional areas such as Engineering, Design and Architecture.

Developing skills: preparing teaching units to meet the need of human resources experts on inclusive educational practices in several areas of knowledge. These professionals work today on a small number, which comes to overload them and prevent them from performing their services effectively.

Training teachers: formal training appropriate to handle the existing demand in the public schools. It is up for managers responsible for the process the organization of training required for teachers, so that all staff receive appropriate training, including preparatory, even if that particular teacher, at the time, does not have any students with disabilities. 
Training family: guiding people who live with disabled students in many different environments and activities of everyday life. Not only the training required to use certain feature AT acquired is important, but all the guidance that aims to help families cope with the student and their specific needs.

Provide emergency care and support: provide a full-time service, via tele-services - such as telephone and internet which expedites the transmission of useful information for families. This service will be essential for those who need help in a variety of everyday situations, when dealing with students with disabilities enrolled in the school network, as well as possible resources for assistive technology used in environments outside the school.

The relevance and originality of Management Model of Assistive Technology Development (MAT) can be evidenced by comparing it with other service delivery models that are already in use, as the classical model of Cook \& Hussey (2002), shown in Figure 3.

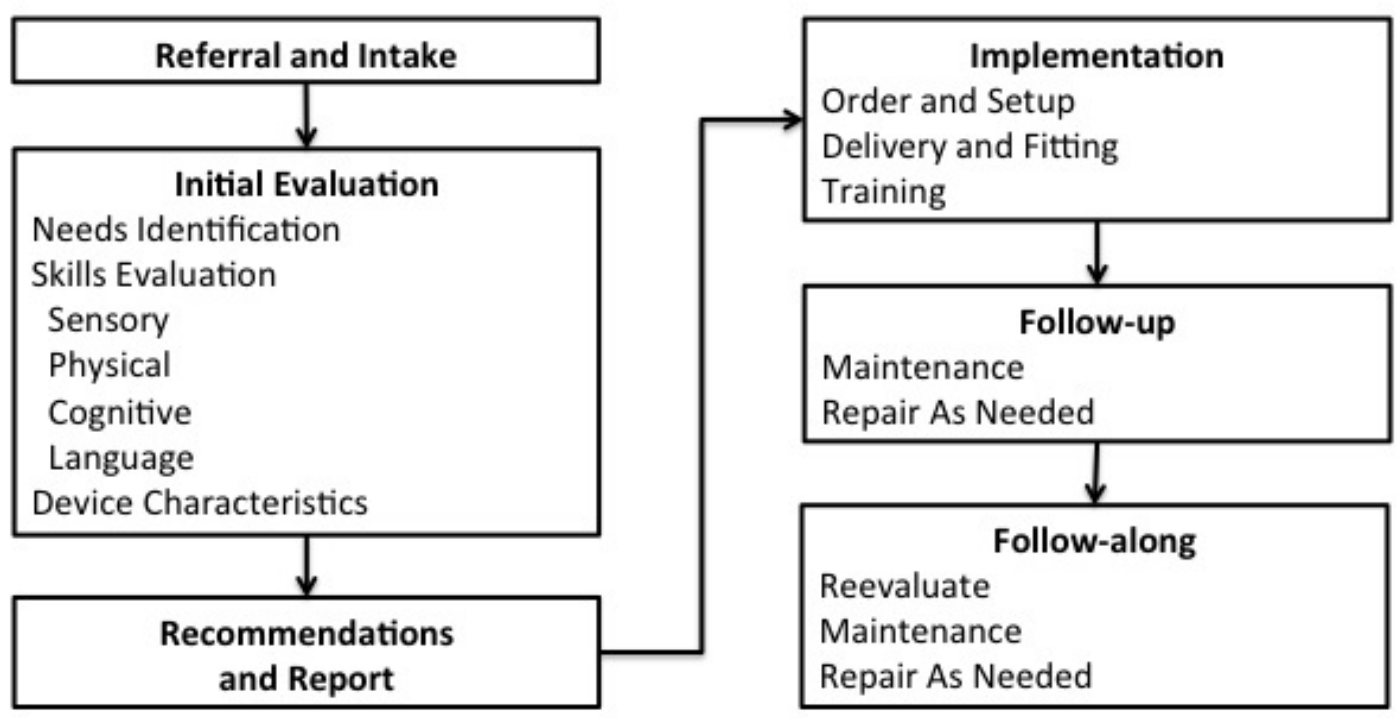

Figure 3. Steps in the Service Delivery Process (adapted from Cook \& Hussey, 2002, p. 98)

The main distinguishing features of traditional models for implementing assistive technology in relation to MAT, proposed in this paper, are related to the fact that MAT has its specific use for the area of education, in a predefined environment in a city southern Brazil, drawn from case studies come from a local reality with perceived needs. Moreover, established models like Cook \& Hussey (2002) are generic and the authors suggest that the steps involved for the delivery of the service offered by AT to be adapted to suit different contexts.

The major contribution of the case study was to confirm the need for the existence of systematization itself, to verify the absence of a systematic process that prescribe activities and resources needed to provide the implementation of AT applicants for learners of surveyed network. Of course, the inclusion of the authors of this work have actually studied also generated the perception of procedures and important details that are useful for the composition of tasks and support resources, as well as the professionals involved in each stage of an ongoing project. An example of this level of detail of the model can be seen in the description of the Analysis Stage.

The Analysis Stage of MAT begins with the activity of 'set people and context of use', as shown in Figure 4. 


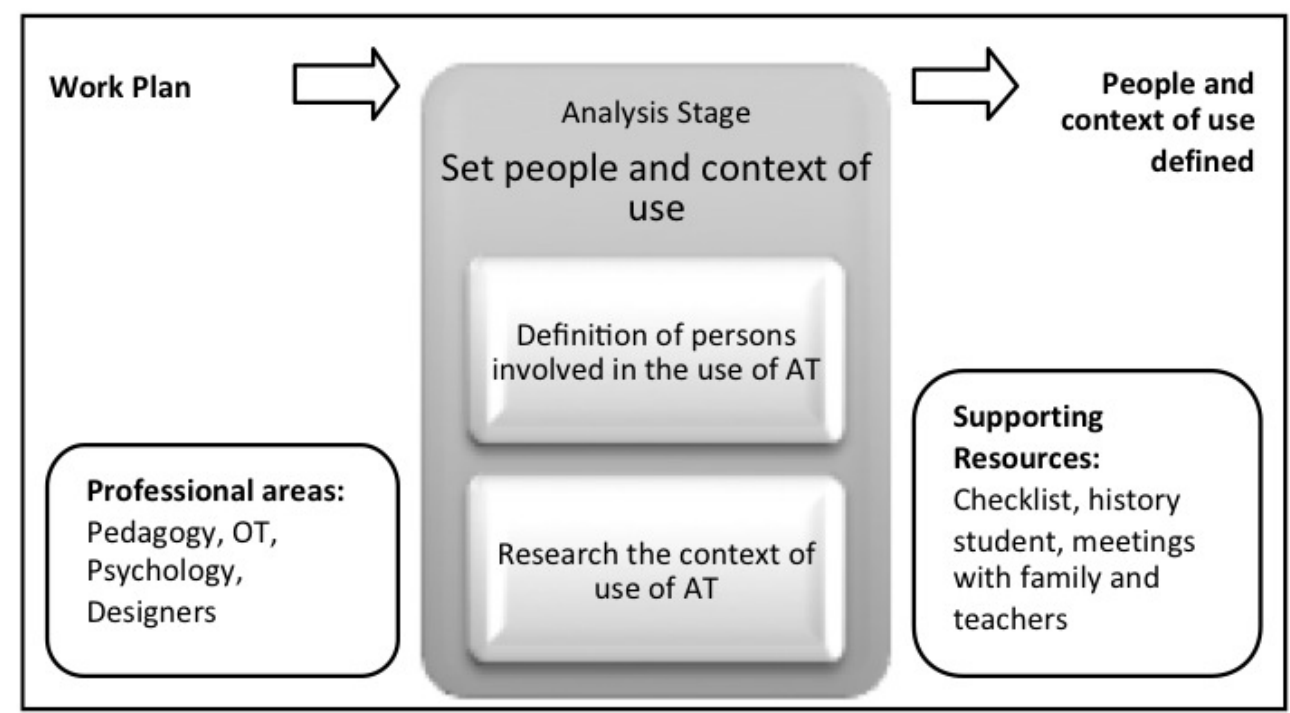

Figure 4. Activity to 'Set people and context of use'

With the work plan in hand, the team can accomplish tasks that relate to the definition of the persons involved in the use of assistive technology in the development and research of context of use of AT. How these tasks should be carried out with the support of checklists, the history of the student and meetings with family and teachers, it is indicated that professionals in the field of pedagogy, psychology and occupational therapy (OT) are involved, but with the direct support of projective professions.

Figure 5 details the second activity of the Analysis Stage of MAT, namely: 'evaluate the user profile functionality'.

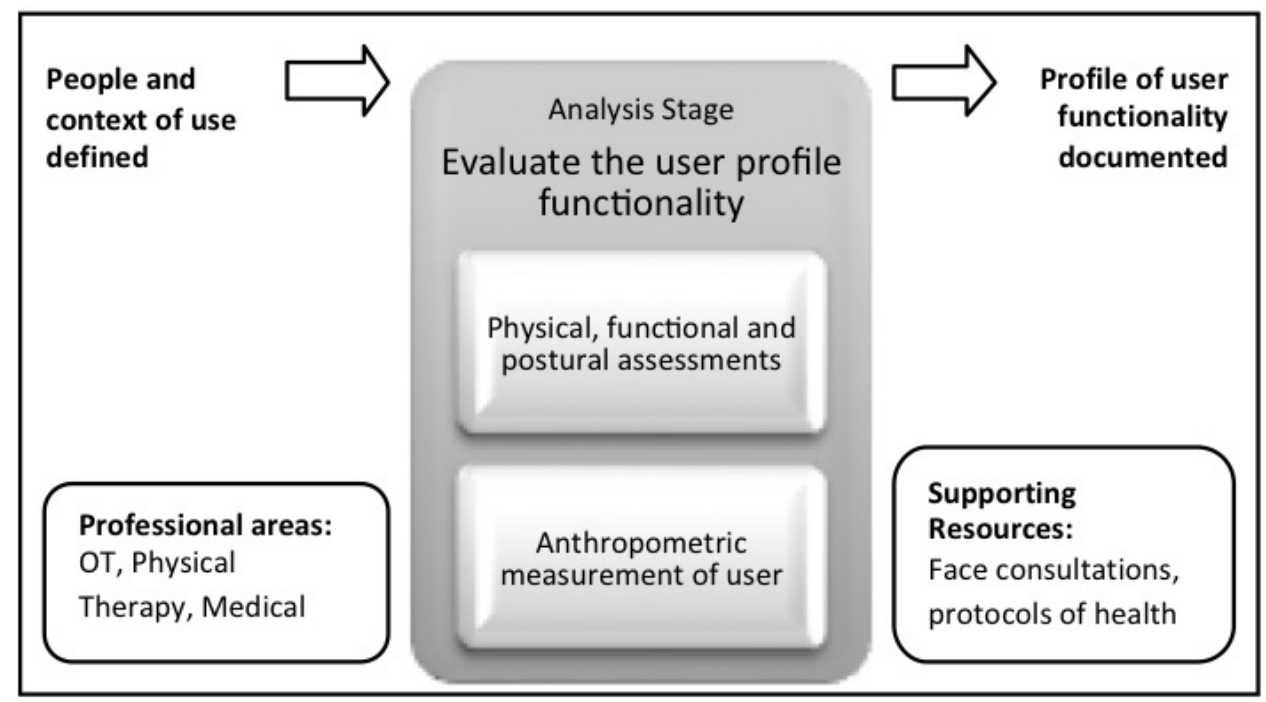

Figure 5. Activity to 'Evaluate the user profile functionality'

As seen in the figure, health professionals such as doctors, physiotherapists and occupational therapists (OT) should perform physical, functional and postural assessments, and anthropometric measurement of the user, in order to document the profile of the student applicant functionality of AT. These data will help to compose the requirements and restrictions for the definition of the technical specifications of the AT. As resources support, on-site consultations with the student and others involved are suggested, by implementing protocols in the area of health, many of them internationally validated. 
The activity 'Raise people's needs' is presented in detail in Figure 6.

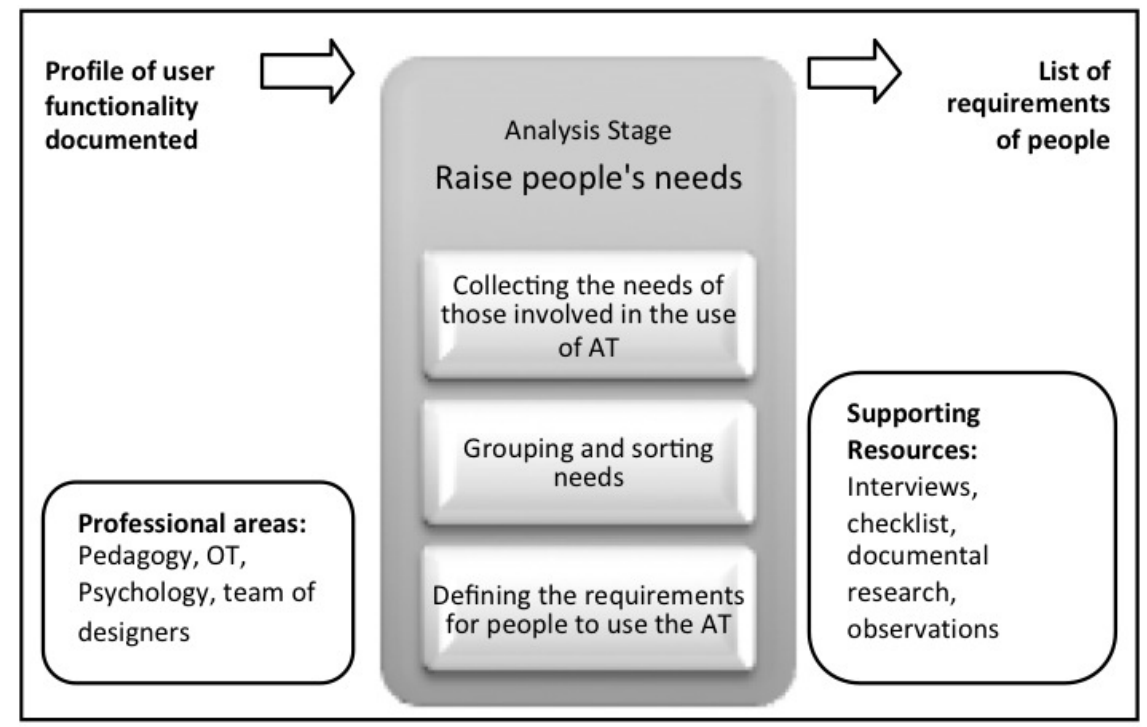

Figure 6. Activity to 'Raise people's needs'

Through the use of supporting resources such as interviews, checklists, observations and documentary research, professionals in the field of pedagogy, OT, psychology and others may collect the needs of those involved with the student applicant. A classified and grouped time, the needs raised, together with the profile of the functionality documented user requirements can be converted into the people involved in the context of use of assistive technology in development. The requirements serve as a basis for defining the technical specifications of the AT, which is the next activity of systematization.

In Figure 7 we observe in detail the activity of 'set technical specifications of AT', the last activity proposed for Analysis Stage of MAT.

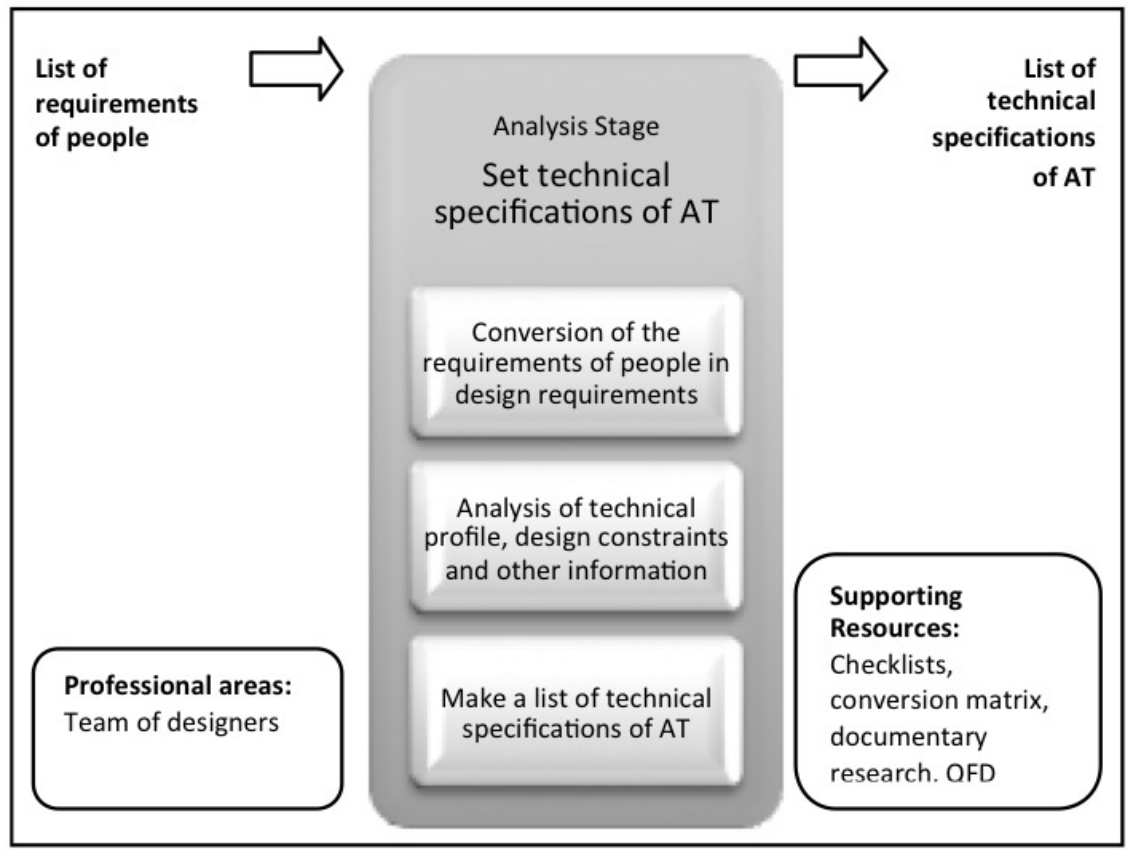

Figure 7. Activity to 'Set technical specifications of AT'

The first task of the activity to 'set technical specifications of $\mathrm{AT}^{\mathrm{T}}$ involves converting the requirements of people in project requirements. In conjunction with the analysis of the technical profile of the AT, the design constraints and other relevant information, then one can draw up a list of technical specifications of AT. In order to fulfill these tasks, 
the team allocated designers can make use of traditional design tools such as checklists, conversion matrix of requirements specifications, documentary research and QFD (Quality Function Deployment).

\section{Discussion}

From the results obtained are presented in which fields, or procedures, the Management Model of Assistive Technology Development (MAT) has added value to managers, parents, teachers and students participating in the reality in which this work fits. The following list the clearest aspects where the MAT provided improvements by the proposed modification of a pre-established theory:

- Obtaining a management model that guides a standardized prescriptive process for the development of AT, in order to guide the work of managers in learning units, as well as family and teachers involved;

- Management Model detailed in stages, activities, tasks, support processes, support resources, professional areas needed and results or deliverables required, resulting in an appropriate level, scrutinized, to reference the managers work;

- Clear definition of professional areas necessary for the completion of each activity during the process, in an interdisciplinary approach;

- $\quad$ Suggested support resources to each model activity, which guides managers not only about which tasks to perform, but how to perform them;

- Precise definition of what outcome is required for each model activity in order to continue the development;

- Existence of Support Processes that go beyond the development of a specific AT, improving the educational reality as a whole and preparing the necessary infrastructure for the development of products and services tailored to the demand;

- MAT covers the process of preparing teaching units, which generates structural and material improvements to the institutions;

- $\quad$ Partnering is predicted in the model as a support process that aims to increase the quality of care in teaching units;

- $\quad$ MAT proposes to develop skills to meet the demand for knowledgeable of inclusive practices professionals in the network;

- The continuing education of teachers figure as key support process to provide the appropriate inclusion of students with disabilities in regular educational network;

- MAT provides training for family members on a periodic basis to deal with the family member with disabilities, and correctly use a given AT;

- $\quad$ Provide emergency care and support is offered to support the process management model to assist people involved in the context of using the AT developed;

- Promotion of proper planning to start any single project, by defining guiding elements: staff, AT's scope, budget, schedule, communication structure and work plan;

- Obtaining the needs of those involved in the context of using the AT directly, allowing the working team approach with families and teachers;

- Evaluation of the user profile functionality performed by qualified professionals and in constant dialogue with other members of the project team;

- Definition of technical specifications which the developing AT must have in order to guide the subsequent design steps;

- $\quad$ Conceptualization of appropriate products and services performed by different and complementary areas such as Engineering, Design, Education and Health, which increases the suitability of the alternatives generated;

- MAT provides autonomy to the work team to select appropriate resources for purchase and delivery to the applicant public, waiving bids and other bureaucracies that hinder appropriate time limits for serving students with disabilities;

- MAT provides that the work team is able to manage the development of new products or services if they are not available or are not feasible for direct purchase; 
- The developed management model proposes to carry out tests before definitely delivering the acquired AT to the student in order to verify the need for possible adjustments;

- The delivery of a specific AT involves training in its use, transmitted to family members and teachers by the staff;

- Assess the satisfaction of the people and monitor the performance of the AT are included in the MAT as fundamental activities during the use stage in order to constantly improve the aspects considered critical;

- $\quad$ People served by a AT developed from the MAT should be able to have proper servicing and maintenance of the resource received;

- $\quad$ The proposed management model provides activities that develop the continuous improvement process through opportunities for improvement identified by staff.

The points listed, therefore, illustrate in a direct way what are the main aspects that can be improved through the use of a specific management model for the development of assistive technology in public educational networks.

Naturally, the research developed has its limitations. Was not the objective of this study, for example, generate a management model suitable for any existing reality in Brazil, and much less in other countries. It was necessary to define very specific aspects for the conduct of the proceedings recorded in this work, starting with the reality studied, which was limited to the case of the municipal education of a single municipality, with its own conditions, requirements and procedures. Another limitation to the study was the need to define an audience with specific characteristics for the sample selected for the case study. Thus, only children with cerebral palsy were selected, knowing that the regular education includes students with diverse needs and disabilities.

It is also proposed that the MAT can not be considered a management model for inclusion, itself, just as it systematizes aspects related to the development of assistive technology, which is one of the actions necessary for a full school inclusion. The Support Processes proposed, but not detailed in the MAT, for example, illustrate that many actions must still be performed at the governmental, institutional and educational levels, so that we can conclude that inclusion of a complete project is underway. It fell to the scope of the Management Model of Assistive Technology Development (MAT), therefore, foster aspects relating to the care of a specific demand, through specific actions in management of the PDP in a unique and previously defined context.

\section{Conclusion}

This article presents reflections and interventions at the level of management for inclusive practices related to the development of products and services that help the daily activities of students with disabilities enrolled in a public school in Brazil. The results, of course, also extend to family members and teachers involved in the life context of students served, whose needs involved in providing physical and cognitive assistance are also met through the developed and delivered resources.

The initial hypothesis raised in this paper, that the various aspects of managing the assistive technology development have lagged behind the growing demand for such resources in regular public schools, was confirmed by conducting research and analyzes based on the method of case study. From a pre-defined theory called MAT framework, could the defended main concepts be taken to a field verification, confirming or refuting certain beliefs about the different constituents of reality, as the teaching units, managers, teachers, family members and the students. From the manifestation of the point of view of each person involved in the process, we managed to build a management model that would address the aspects considered essential for an adequate development of assistive technology for the study context. The result was the MAT detailed in this document, the Management Model of Assistive Technology Development.

While not the definitive solution to the problem of social inclusion in public schools in Brazil, nor has this distant claim, the MAT can be considered an initial step on the long road to be traveled. This path leads to an ideal condition for the development of adequate resources for use by children who need to have stimulated their potential to develop. If that personal development does not occur with some students, that is not so, at least, by negligence in providing what is in the scope of the educational systems in terms of structure, products and services that can assist - and often eliminate - the disabilities of the human being inserted there. 


\section{References}

Afacan, Y., \& Demirkan, H. (2010). A priority-based approach for satisfying the diverse users' needs, capabilities and expectations: a universal kitchen design case. Journal of Engineering Design, 21(2\&3), 315-343. http://dx.doi.org/10.1080/09544820903303423

Baxter, M. (1995). Product design: a pratical guide to systematic methods of new product development. London: Chapman \& Hall.

Brazil. (1989). Federal Law 7.853/1989 of October 24, 1989. Retrieved from http://www.planalto.gov.br/ccivil_03/Leis/L7853.htm

Carse, B.; Thomson, A., \& Stansfield, B. (2010). Use of biomechanical data in the inclusive design process: packaging design and the older adult. Journal of Engineering Design, 21(2\&3), 289-303. http://dx.doi.org/10.1080/09544820903303456

Clarkson, J., \& Coleman, R. (2010). Inclusive design. Journal of Engineering Design, 21(2\&3), 127-129. http://dx.doi.org/10.1080/09544821003693689

Cook, A. M., \& Hussey, S. M. (2002). Assistive technologies: principles and practice( $2^{\text {nd }}$ ed.). Saint Louis.

Fonseca, F. L., \& Lima, C. L. A. (2004). Paralisia Cerebral: Neurologia, Ortopedia e Reabilitação. Rio de Janeiro: Guanabara Koogan.

Goodman-Deane, J., Langdon, P., \& Clarkson, J. (2010). Key influences on the user-centred design process. Journal of Engineering Design, 21(2 \& 3), 345-373. http://dx.doi.org/10.1080/09544820903364912

Gyi, D., Cain, R., \& Campbell, I. (2010). The value of computer-based product representations in co-designing with older users. Journal of Engineering Design, 21(2\&3), 305-313. http://dx.doi.org/10.1080/09544820903303449

Johnson, D., Clarkson, J., \& Huppert, F. (2010). Capability measurement for inclusive design. Journal of Engineering Design, 21(2\&3), 275-288. http://dx.doi.org/10.1080/09544820903303464

Marshall, R., Case, K., Porter, M., Summerskill, S., Gyi, D., Davis, P., \& Sims, R. (2010). HADRIAN: a virtual approach to design for all. Journal of Engineering Design, 21(2\&3), 253-273. http://dx.doi.org/10.1080/09544820903317019

Nickel, E. M. (2012). Sistematização da implementação de tecnologia assistiva para o contexto educacional. $264 \mathrm{f}$. Thesis (Ph.D. in Production Engineering). Graduate Program in Production Engineering from the Federal University of Santa Catarina. Florianópolis.

Otto, K. N., \& Wood, K. L. (2001). Product design: techniques in reverse engineering and new product development. New Jersey: Prentice Hall, inc.

Pahl, G., \& Beitz, W. (1996). Engineering design: a systematic approach. (2 ed). London: Springer.

PMI Standards Committee. (2000). Project Management Body Of Knowledge. Pennsylvania: Project Management Institute Publications.

Pugh, S. (1990). Total design: integrated methods for successful product engineering. Massachusetts: Addison-Wesley.

Roozenburg, N. F. M., \& Eekels, J. (1995). Product design: fundamentals and methods. Chichester: Wiley.

Rozenfeld, H., Forcellini, F. A., Amaral, D. C., Toledo, J. C. de., Silva, S. L. da, Alliprandini, D. H., \& Scalice, R. K. (2006). Gestão de desenvolvimento de produtos: uma referência para a melhoria do processo. São Paulo: Saraiva.

Stoecker, R. (1991). Evaluating and rethinking the case study. The Sociological Review, 39, 88-112. http://dx.doi.org/10.1111/j.1467-954X.1991.tb02970.x

Yin, R. K. (2003). Case study research: design and methods( $3^{\text {rd }}$ ed.). Sage Publications. 